\title{
Solar Home Lighting System with AC and DC Loads
}

\author{
Aaditya Jain ${ }^{1}$, Mrs. Kusum Tharani ${ }^{2}$, Himanshu Dhall ${ }^{3}$, Nikhil Kumar Singh ${ }^{4}$, \\ Saarthi Bhatia ${ }^{5}$, \\ ${ }^{I}$ Electrical and Electronics Engineering Bharati Vidyapeeth's College of Engineering \\ ${ }^{2}$ H.O.D., Electrical and Electronics Engineering Bharati Vidyapeeth's College of Engineering \\ ${ }^{3}$ Electrical and Electronics Engineering Bharati Vidyapeeth's College of Engineering \\ ${ }^{4}$ Electrical and Electronics Engineering Bharati Vidyapeeth's College of Engineering \\ ${ }^{5}$ Electrical and Electronics Engineering Bharati Vidyapeeth's College of Engineering
}

\begin{abstract}
The main objective of the study is to provide alternate lightning system by using solar energy. The system taken for study consists of a Solar panel of 10W, a 12 V battery, a Solar charge controller, Multi vibrator IC(CD 4047),MOSFET(IRF Z44N),Step down transformer(12-0-12). It provides solution to the gap between energy demand and energy availability. The charge controller maintain the flow of charge to the battery i.e, it provides protection against the overcharging and deep discharging of the battery. At the same time PV technology is the strongest growing electricity generation technology, which also provides a solution to the global warming. Almost every portion of the tropical India is favorable for adopting this technology. PV energy is being used across the world with different conversion technologies as autonomous power packs and as grid-integrated systems. Type of converter and load depends on the application to which it is intended. The study presents the analysis of solar powered home lighting system practically and verifies the design of the system for reliable and optimal performance.
\end{abstract}

Keywords: Inverter, battery, charge controller, transformer

\section{Introduction}

Solar home lighting system are photovoltaic systems which offers cost effective solution to supply energy to remote off- grid areas. Solar energy sustains life on Earth for all plants, animals and people because it provides an exciting solution for all the societies to meet their needs for clean, abundant sources of energy in the future. The main source of solar energy is the nuclear reaction at the core of the Sun, where the energy comes from the conversion of hydrogen into helium. Solar energy is transmitted to the Earth in the form of electromagnetic waves, which can also be represented by photons. The Earth, therefore, is essentially a huge solar energy collector receiving large quantities of solar energy which can be seen in various forms such as plant photosynthesis, and evaporation of the oceans resulting as rain which forms rivers and provides hydropower energy.

In some rural areas electrification is not possible so in that area SHS can be used to meet a household's energy demand fulfilling basic electric needs. [9] Globally SHS provide power to hundreds of thousands of households in remote locations where electrification by the grid is very costly or not possible. SHS usually operate at a rated voltage of $12 \mathrm{~V}$ direct current (DC) which we get from the lead acid battery and provide power for low power DC appliances such as lights, radios and small TVs for about three to five hours a day. Furthermore SHS use appliances such as inverter in which we have used multivibrator IC and two MOSFETs, so by using inverter we can change $12 / 24 \mathrm{~V}$ power to 240VAC power for larger appliances.

A SHS typically includes one or more PV modules consisting of solar cells, a charge controller which distributes power and protects the batteries and appliances from damage and at least one battery to store energy for use when the sun is not shining because at night there is no sun so output voltage at the panel is zero. [1]The study consists of energy source by means of solar energy. The Photovoltaic panel converts solar energy directly into electrical energy. The electrical energy is given to charge controller. The Charge controller regulates the power and provides overcharging protection and deep discharging protection to the battery. [7] Regulated power is stored in the lead acid battery. The stored energy is in DC form which is further converted into $\mathrm{AC}$ by means of a medium power inverter.

\section{Methodology}

The proposed system uses a monocrystalline solar panel because it is more efficient than polycrystalline panel, so when light strikes the surface of the panel then we get $12 \mathrm{~V}$ output which can be convertd into $5 \mathrm{~V}$ by voltage regulator IC and this $5 \mathrm{~V}$ is fed as an input to the charge controller. [3] The battery is charged using a solar panel with a charge controller in between them. The charge controller 
is used to protect the battery from overcharging and deep discharging. Once the battery is charged, a D.C. load could be directly connected to the battery. In addition to this, an A.C. load could be connected to the inverter, which is directly connected to the charge controller. The inverter is used to convert the D.C. power, supplied by the battery, into A.C. power to operate the A.C. load.

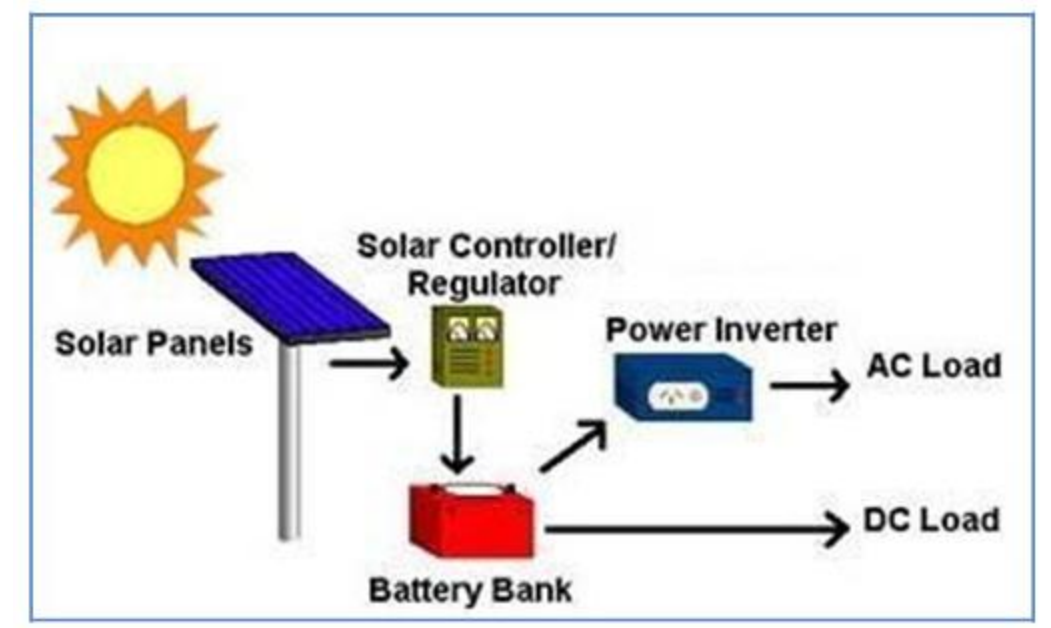

Fig 1: Block diagram of the work

\section{A. Solar Panel}

\section{Hardware Description}

Solar panels or more technically photovoltaic (PV) panels are a solar home electric system's enabling component. There can be various types of solar panel but mainly there are only three types of solar panel i.e, monocrystalline,polycrystalline and amorphous thin film type solar panel. Monocrystalline cells are being sliced out from ingot of pure crystalline. They are black in colour and they can absorb maximum sunlight falling on the surface if set at correct angle.[8]The efficiency of monocrystalline cell is around 19$20 \%$. Polycrystalline cells are being made of pure silicon cut offs, Unlike monocrystalline their cells are not perfectly allinged in one direction and thus interconnection losses may occur which reduses its efficiency to $13-15 \%$. Amorphous thin film efficiency is around 6-10\%. The Panels are made of wafers or cells of semiconductor material that use sunlight (photons) and the photovoltaic effect to generate direct current (DC) electricity.
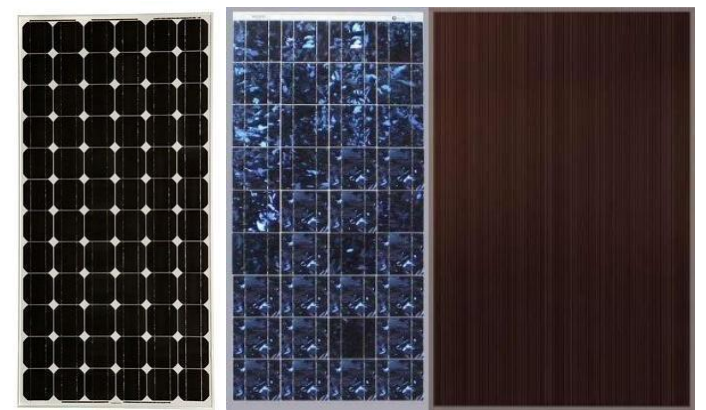

Fig 2: Solar panel types: (a) mono-crystalline silicon, (b) poly-crystalline silicon, and (c) amorphous.

The different cell technologies are used to represent different energy conversion efficiencies and manufacturing techniques which are used in trying to reduce the cost of photovoltaic generated electricity. The photovoltaic technology is constantly evolving day by day in the direction of better conversion efficiency and lower cost. Each solar cell can generate a predetermined voltage and current under certain manufacturing and physical constraints. A solar panel is a series and parallel combinations of identical cells to generate the desired power output (current and voltage). Panels are assigned a power rating in watts which depends on the maximum power they can produce under ideal sun and temperature conditions. By knowing the rated power output we can determine how many panels are required to meet the electrical load demands. [5]Multiple panels combined together are called solar arrays. There is a directly proportionality between solar panel cost and output power. The solar panel is approximately $50 \%$ of the total initial equipment cost of a SHS. 


\section{B. Comparator IC}

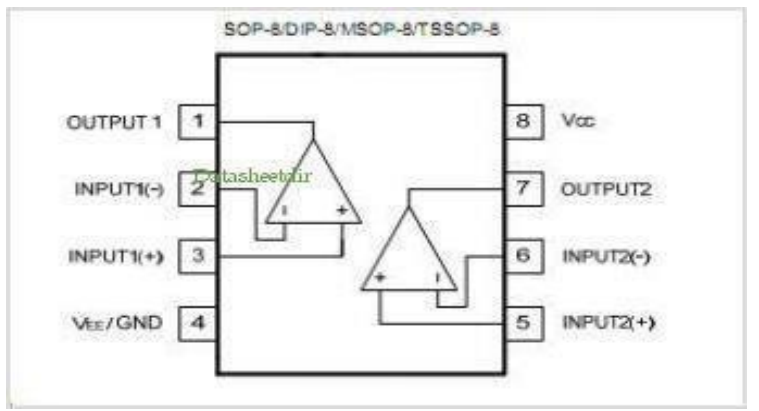

Fig 3: Comparator IC

A voltage comparator is an electronic device which compares the two input voltages and gives the output of the voltage which is greater. It's easy to create a voltage comparator from an op amp, because the polarity of the op-amp's output circuit depends on the polarity of the difference between the two input voltages. In one Op amp we can compare two sets of inputs.

\section{Zener Diode}

The main application of Zener diode are as a voltage regulator and overvoltage protection. Overvoltage protection is achieved by using Zener diodes since there is a current flowing through the Zener diode even when the reverse bias voltage exceeds far away from a certain value.

\section{Zener Diode as a Voltage Regulator}

The term regulator refers to regulates or controls. Zener diode can work as a voltage regulator if it is introduced in a circuit as shown below so by doing so we get a constant output voltage across the diode. The circuit is driven by a current voltage source. As we know that if the voltage across the diode exceeds a certain value then the Zener diode would draw excessive amount of current from the supply. The basic diagram of zener diode as a voltage regulator is shown.

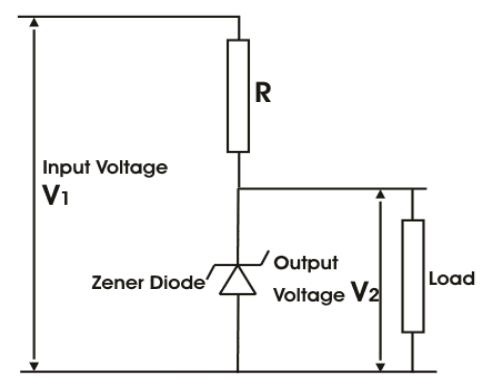

Fig 4 : Zener diode as a voltage regulator

To limit the current through the Zener diode we use a series resistance $\mathrm{R}$ whose value can be chosen from the following equation

$$
\text { Resistor value }(\text { ohms })=\frac{V_{1}-V_{2}}{\text { zener current }+ \text { load current }}
$$

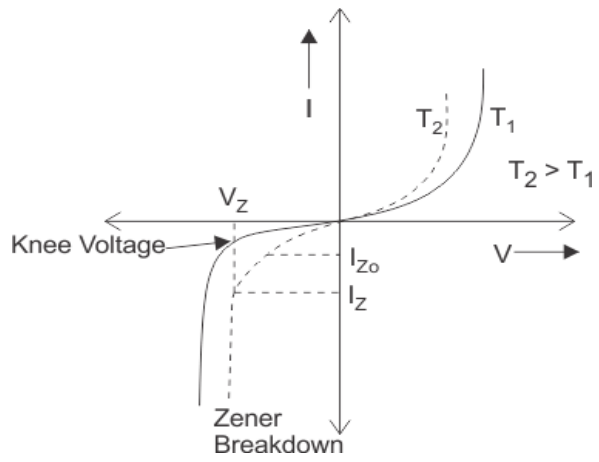




\section{Charge Controller}

Fig 5 : Characteristics of Zener diode

[4]The function of the charge controller is to maintain battery life by preventing battery overcharging by the solar panels and deep discharging by the electrical loads. [2]Either condition will lead to severely reduced battery lifespan or harm it. Charge controllers come in all forms such as different sizes, protection and monitoring features. The selection of charge controller depends on the size of installed solar panel(s) and the complexity of loads and future expansion possibility. Different charging and maintenance algorithms or techniques are used which depends upon the state and the type of the battery used.

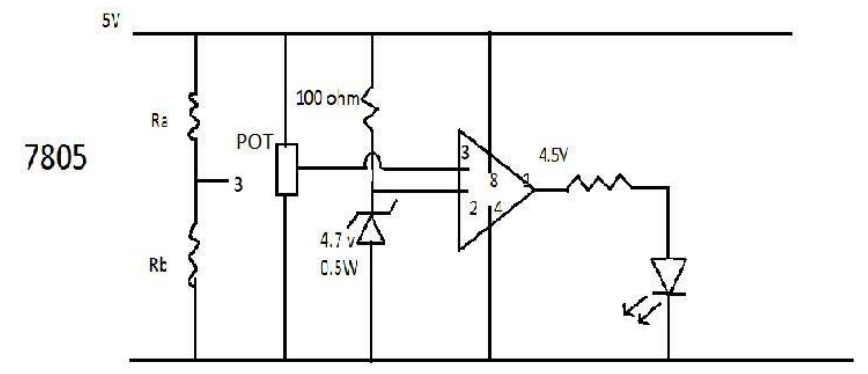

In case of Overcharging:

Output at Pin $3>$ Output at pin 2

Output at pin $1=1$

Vin $=12.6 \mathrm{~V}$

At pin 3, we require voltage $>4.6 \mathrm{~V}$

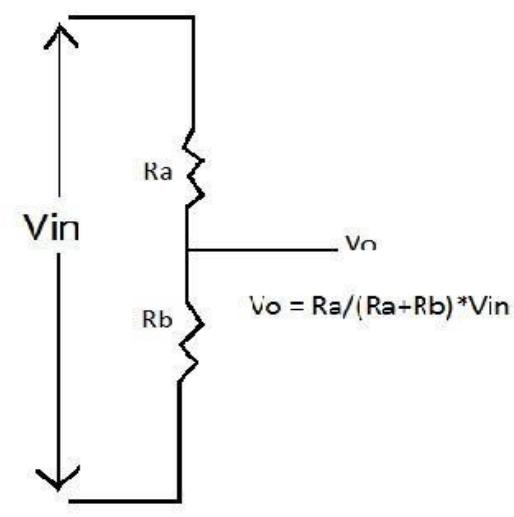

4.7 $=\mathrm{Ra} /(\mathrm{Ra}+\mathrm{Rb}) * 12.6$ (Overcharging equation) Lets assume $\mathrm{Ra}=1 \mathrm{~K} \Omega$

So from above equation we get, $\mathrm{Rb}=1.5 \mathrm{~K} \Omega$

In case of Deep discharging:

Output at pin $3<\operatorname{pin} 2$

Output at pin $1=0$

We have $\mathrm{Vin}=11.6 \mathrm{~V}$ and $\mathrm{Vo}=4.7 \mathrm{~V}$

$4.7=\mathrm{Ra} /(\mathrm{R} 1+\mathrm{Rb}) * 11.6$

Lets assume $\mathrm{Rb}=1 \mathrm{~K} \Omega$

So from above equation we get, $\mathrm{Ra}=1.2 \mathrm{~K} \Omega$

\section{E. Battery}

Almost all solar electrical applications uses a lead-acid type of battery chemistry to store energy. [6]This is because of the battery's storage capacity to cost ratio, their wide availability, technical simplicity, and support infrastructure. 


\section{DISCHARGING PROCESS}

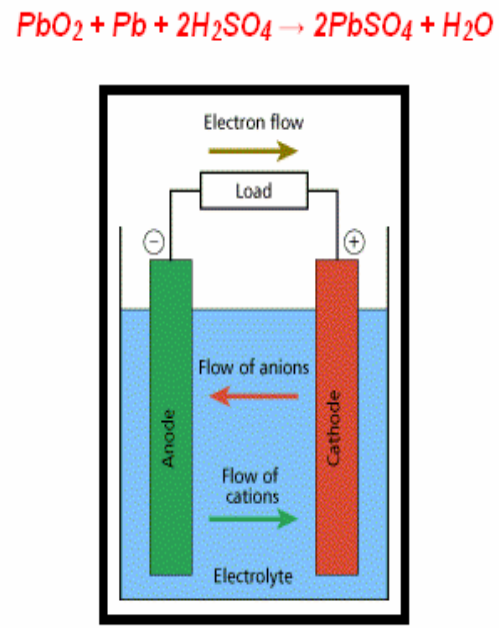

\section{CHARGING PROCESS (Reverse of Discharging Process) \\ $2 \mathrm{PbSO}_{4}+\mathrm{H}_{2} \mathrm{O} \rightarrow \mathrm{PbO}_{2}+\mathrm{Pb}+2 \mathrm{H}_{2} \mathrm{SO}_{4}$}

Fig 6: Discharging and Charging processes of the battery

A lead-acid battery is an electrochemical device that stores chemical energy and convert it as electrical energy by electrochemical process upon demand. When a battery is connected to an external load, such as a light, fan or motor etc. chemical energy is converted to electrical energy and direct current flows through the circuit from cathode to anode of the battery and an electron will move in a direction opposite to current i.e. from anode to cathode.

\section{F. LOADS}

[2]Loads are electrical appliances that draw power from the battery. As we know that maximum home electrical appliances are AC power and to use AC powered appliances in a SHS, a DC-AC power inverter will be required. The inverter itself acts as a load because it can draw power (stand-by power consumption) and conversion efficiency losses are also occurred in an inverter. In this case all the AC appliances connect to the inverter can also get its power from the battery. In many SHS projects, an inverter is not included due to cost constraints and system complexity. So in those cases we include DC appliances such as CFL and LED lights, small radios, and small DC powered TVs are connected directly into the $12 v$ DC SHS circuit. It is very cost effective and efficient to use DC-only SHS due to the typical low power requirements of DC appliances and it also reduce system complexity.

\section{G. N channel MOSFET(IRFZ44N)}

Unlike bipolar transistors, MOSFET is voltage controlled. While in case of BJT we you have to calculate the base resistance very carefully according to the amount of current being switched because it is a current controlled, but this is not so with a MOSFET. Just we have to apply enough voltage to the gate and the switch operates. MOSFET has a very high input impedance. MOSFET has high input impedence. To use a MOSFET as a switch, you have to keep its gate voltage (Vgs) higher than the source voltage. If you connect the gate to the source $(\mathrm{Vgs}=0)$ it is turned off. For example we have a "standard" MOSFET IRFZ44N which turns on when Vgs is between $10 \mathrm{~V}$ and $20 \mathrm{~V}$. For N-channel MOSFET the reason we usually put the load at the Drain side is because of two reasons. Firstly, Source is usually connected to GND. Secondly, If load is connected at the source side and we put the ground at the drain sides, then we have to trigger the MOSFET at the higher Vgs so there will be insufficient or very less current flow between source and drain than expected.

\section{H. Inverter}

In an inverter we use various components such as Multivibrator IC(CD4047), two MOSFETs, Step Up Transformer, Timing Components etc. The advantage of using multivibrator IC is that by using it we get a perfect Square Wave, which has three forms are: First at pin 13 of IC will be basic 
frequency, Second is pin 11 will be half that of basic frequencies, And thirdly at pin 10 is half the frequency of basic frequency. but will has to invert the signal to 180 degrees. So is there a characteristics opposite to the second output.

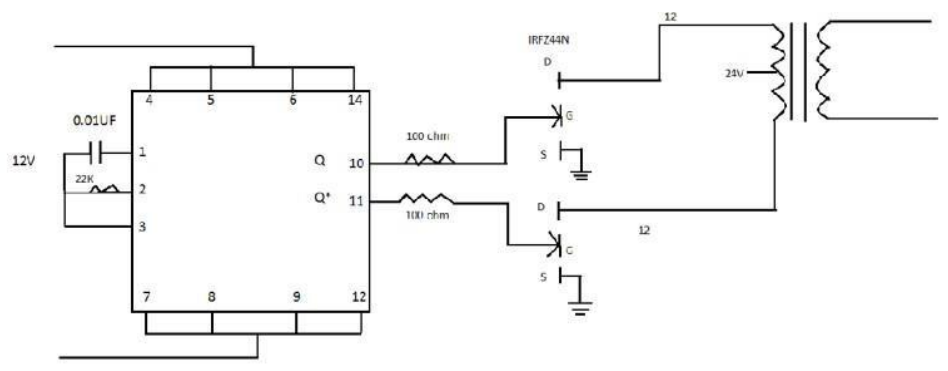

Fig 7: Inverter

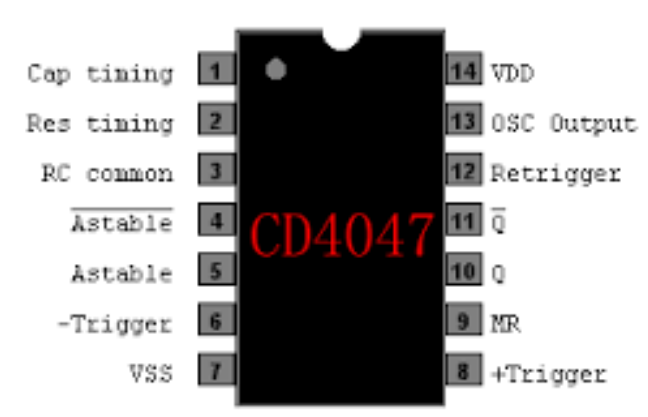

Fig 8 : Multivibrator IC- CD4047

This tested design converts $12 \mathrm{~V}$ DC from the storage battery of any solar power system to $230 \mathrm{~V}$ AC through which we can run various AC Loads such as an energy saving CFLs. The solar powered inverter circuit, optimised for CFL loads, uses IC CD4047 as a freerunning astable oscillator. Capacitor and resistor at pin 1 and 2 are timing components. The pulse repetition rate of IC is determined by the value of $4.4 \times C 2 \times R 2$. IC generates complementary square wave signals at its output pins 10 and 11 . The two MOSFETs serve as drivers for the high-voltage generator, realized using step-up transformer. Note that an ordinary (AC $230 \mathrm{~V}$ to $12-0-12 / 5 \mathrm{Amp}$ ) step-down transformer is here used for reverse function (step-up) and its output is available at AC mains outlet. You can light up two to four low wattage (ie $11 \mathrm{~W}$ at $\mathrm{AC}$ 230V) ready-made Compact Flourescent Lamps (CFLs) using this portable solar power inverter circuit.

\section{Results}

\section{A. During the operation}

Photovoltaic panel thus directly feeds D.C. loads and charges the battery simultaneously when solar energy is available. Battery can be used directly to drive D.C. loads whereas A.C. loads can be fetched by attaching an inverter between Battery and the load.

\section{B. During the internal resistance test}

Photovoltaic panel always has some internal resistance. This resistance, together with load resistance results in drop of the voltage when load is applied across the panel. To have faithful study of the performance of the panel, it is necessary to know its internal Resistance. So that same may be taken into account while studying various characteristics. Internal resistance of the panel comes out to be $13.6 \mathrm{ohm}$. There is a drop of 8.29 volts due to this internal resistance. Though internal resistance is bound to exist, it should be kept as low as possible in order to obtain optimum performance of the solar panel.

\section{During the Charge test}

The charge time can be calculated as shown: The $10 \mathrm{~W}$ solar panel puts about $10 \mathrm{~W} / 12 \mathrm{~V}=0.83 \mathrm{~A}$ under optimum conditions. The presence of the such optimum conditions is assumed to be present for approximately 6 hours per day. The charge delivered will be $0.83 \mathrm{~A} * 6 \mathrm{Hrs}=5 \mathrm{~A} \mathrm{Hrs} \mathrm{per} \mathrm{day.} \mathrm{Now,} \mathrm{the} \mathrm{battery} \mathrm{rating} \mathrm{is} 7 \mathrm{~A}$ hrs. So, the charge time will be $7 \mathrm{~A} \mathrm{Hrs} / 0.83 \mathrm{~A}=8.4 \mathrm{Hrs}$. 


\section{During the Discharge test}

From the study it is found that developed system can deliver power for nine continuous hours

\section{Conclusion}

The overcharge and under charge protections are used so that during these conditions to make the user aware of these conditions. The setting of these protections is achieved through potentiometer.

Not only Energy consumption to manufacture the solar panels of Solar Home System with LED bulbs is $1.44 \mathrm{MWht}$, which is $25 \%$ lower than that of the Solar Home System(SHS) with tube lights, but also $3 \mathrm{~W}$ of power saving per fixture is achieved. Photovoltaic technology is the most promising source to solve the world's energy deficit problem in future. By 2050, PV has the potential to provide a top limit of around 10 to $15 \%$ of the world's electricity use. This would reduce the dependance on the conventional methods, and since the life of a solar panel is more than 20 years, it would be economical in long run.

From all the above studies, it is concluded that the solar PV LEDs lighting system is better than other lighting sources because this system can be used as home appliance, residential and commercial process with some switching devises, and with some controlling equipment. The power performance of this system is good because it does not take more power as compared to other lighting systems.

\section{References}

[1]. Alkos Baldauf, "A smart home demand-side management system considering solar photovoltaic generation”, IEEE 2015 5th International Youth Conference on the Development in the Renewable Energy Technology (ICDRET)

[2]. Taoufiku Islam; M. Abdul Awal.”Efficient Load and Charging Method for Solar Powered Home Lighting System”, IEEE 2014 $3^{\text {rd }}$ International Conference on the Developments in Renewable Energy Technology(ICDRET), Pages:1-3

[3]. Biswajit Biswas, Sujoy Mukherjee, "A Comparative Study of Low Cost Solar Based Lighting System and Fuel Based

[4]. Lighting System for Remote off Grid Location in India”, International Journal of Modern Engineering Research(IJMER), Vol. 3, Issue. 5, September 2013, 2249- 6645

[5]. A. S. Werulkar; P. S. Kulkarni. "Design of a solar charge controller with microcontroller based soft switching buck converter", IEEE 2012 International Conference on Power Electronics, Drives and Energy Systems (PEDES)

[6]. Tarujyoti Buragohain, "Impact of Solar Energy in Rural Development in India", International Journal of Environmental Science and Development, Vol. 3, No. 4, August 2012,334-338

[7]. Savitha G. Kini. "Design and development of energy efficient retrofit LED fixture for solar powered home lighting system",Annual IEEE India Conference, Pages: 1 - 4

[8]. L. Suresh, G. R. S. Naga Kumar, Dinesh. V. R. Gopal Krishna, Design, Development \& Simulation of Solar Lighting System, International Journal of Engineering Research and Applications, Vol. 1, Issue 3, 991-996

[9]. Sree Manju, B Ramaprabha, R Mathur B.L, Design and Modeling of Standalone Solar Photovoltaic Charging System, International Journal of Computer Applications, Volume 18- No.2, March, 2011,0975 - 8887

[10]. Werulkar, A. S., Kulkarni, P. S., and Sahusakde, A., 2010, "Simulation and Energy Balance Study in Solar Home Lighting System," All India Seminar on Power System: Control, Operation and Maintenance (PSCOM-2010), Chandrapur, India, December 4-5, pp. 83-88. 